\title{
Study on Semi-solid Magnesium Alloys Slurry Preparation and Continuous Roll-casting Process
}

\author{
Shuisheng Xie, Youfeng He and Xujun Mi \\ State Key Laboratory of Nonferrous Metals and Processes \\ General Research Institute for Non-ferrous Metals
}

China

\section{Introduction}

Magnesium and its alloys, as the lightest functional and structural materials, have great increasingly application in the automobile, electronic and aeronautical industries due to their low density, high specific stiffness and strength, good heat conductivity, high electromagnetic interference shielding and damping capabilities, etc. However, at present the major problem to the application of magnesium alloys is still lack of suitable forming process.

As a new type of metal forming method, Semi-solid metal (SSM) processing technology has attracted close attention all over the world, since M.C Flemings in MIT firstly introduced this concept in 1970s (Spencer et al., 1972), (Flemings, 1991). Compared with the conventional processes, SSM process has many advantages: higher viscosity than fully liquid, leading to laminar flow and even filling of a die; low solidification shrinkage, leading to more precise dimension product; lower casting temperature and less latent heat resulting in less thermal shock to the die. Compared with solid forming processed, SSM process needs lower loads and can fill more complicated shapes and thinner sections (Xie, 2002). The mechanical properties of SSM product are close to the forged product. So, it is significant to combine the semi-solid process techniques with continuous roll-casting techniques to produce the high quality magnesium alloy strip with non-dendritic structure. However, the key of SSM process is to prepare non-dendritic structure semi-solid magnesium slurry with rosette or globular microstructure or billets with non-dendritic structure. Usually, the nondendritic structure can be obtained by continuous stirring or controlling nucleation and growth processes during the early stages of solidification.

In recent years, many new method of the semi-solid slurry preparation have been developed. These include UBE's new rheocasting (NRC) process (Hall et al., 2000) and the Cooling Slope method (Haga \& Suzuki, 2000; Haga et al, 2004; He et al, 2009); the SLC (subliquids casting) process (Jorstad et al, 2002); the "Continuous Rheoconversion Process" (CRP) (WPI, 2002), the SIMA (Strain-Induced Melt Activation) Process, the SEED (Swirled Enthalpy Equilibration Device) Process; the SCR (Shear-Cooling Roll) process and etc. In essence, all of the above-mentioned processes utilize the same fundamental concept: nucleation and dispersion of the nuclei to achieve the semi-solid structure as the alloy melt is cooled below the liquidus temperature. 
In this chapter, a new process named "Damper Cooling Tube (DCT) method" for preparing semi-solid magnesium alloy slurry was introduced (Xie et al, 2004 and 2007; Yang et al, 2007), which absorbs the characteristics of "new MIT method" and "Cooling Slope method". Numerical simulation and experiment on the preparation process of semi-solid AZ91D slurry using DCT method was carried out based on CFD software Flow 3D. The distribution of the flow field, shearing rate and solid fraction were obtained. The effects of processing parameters such as the position and dimension of the wedge block, fall head and gap size on the slurry properties were investigated in detail, which provides effective guidelines for DCT structure design and optimization of processing parameters. According to the numerical simulation results, the actual experiment for preparing semi-solid AZ91D slurry using DCT method was done. In addition, numerical simulation on semi-solid continuous roll-casting process of magnesium AZ91D alloy using a two-dimensional incompressible non-Newtonian flow model was studied for getting the optimizing processing parameters. According to the simulation results, semi-solid continuous roll-casting process (CRP) experiment for AZ91D was investigated.

\section{The damper cooling tube method}

The DCT device consists of five basic functional units: a pouring system, a cooling system, a heating system, a stirring system and a second temperature adjusting system, as shown in Fig.1 (Xie et al, 2004). The pouring system is designed to pour molten alloy at the predetermined temperature into a container, and need to keep stated height of molten alloy. The cooling system is a cooling tube and can effectively adjust the cooling rate of the molten alloy passing through the cooling tube and therefore it is convenient to adjust the velocity of nucleation as required. The stirring system is introduced to stir the molten alloy uniformly while it flows through the cooling tube. The heating system is to clear the alloy solidified in the inner wall of the cooling tube when the system appears some problems. The second temperature system is designed to adjust the temperature of the slurry from the cooling tube, which can accurately control the solid fraction of semi-solid slurry.

Firstly, the molten alloy is poured into the container from the holding furnace and at the same time some protection gas is inlet the container so as to separate the molten alloy with high temperature from air and thus avoid the oxidation or inflammation of molten alloy. When the molten alloy (several degrees above the liquidus temperature) in the container is poured into the damper cooling tube, due to the cooling system around the tube outer wall, the copious fine nucleation of primary particles are produced and adhere to inner wall of the cooling tube. Crystal nucleuses grow up quickly and then are divorced from the tube wall into molten alloy because of the impact of molten alloy. The molten alloy is stirred by the stirring system and uniform semi-solid slurry is obtained. Finally, the slurry flow into the nether container and under gas protection the semi-solid slurry is adjusted to an expected solid fraction. It can be directly rheo-casted or rheo-formed into work pieces.

Because the height (fall head) of the molten alloy in the container is a driving force to flow, the flow velocity of molten alloy passing through cooling tube is mainly dependent on the height of molten alloy. Therefore, the height of molten alloy in the container needs to be kept steady and it should be determined by experiment. So, in this chapter the semi-solid slurry preparation process by DCT method was simulated based on the FLOW3D software. Effects of the position of wedge block, the gap size between wedge block and the inner wall of cooling tube and height of wedge block on the slurry flow and stirring were investigated. 
In addition, the processing parameters were optimized by numerical simulation, which provides theoretical guide for the preparation of semi-solid slurry by DCT method.

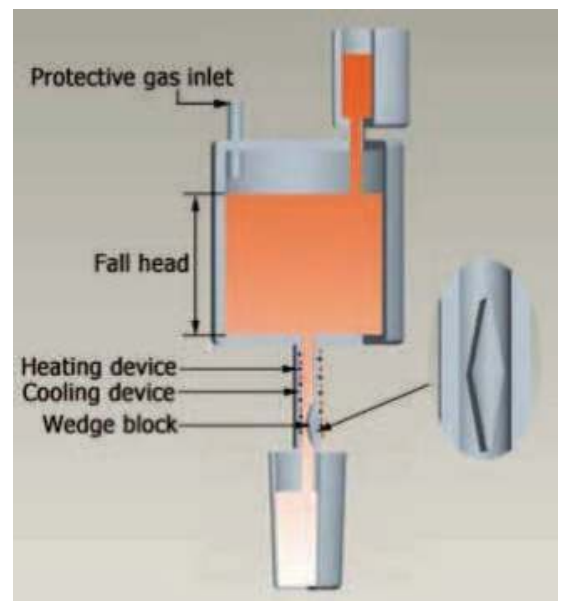

Fig. 1. The DCT with sphenoid damper

\section{Numerical simulation and experiment on DCT method}

\subsection{Mathematical modeling}

Three-dimensional incompressible non-Newtonian flow with heat transfer was considered, which was described by the continuity equation, the Navier-Stokes equation and the energy equation. These equations were solved by the FLOW3D software for a steady-state solution. Due to the velocity fluctuation of flow field of DCT, the turbulent model of FLOW3D was selected in this paper. For momentum transport, the turbulent kinetic energy $k$ and its dissipation $\varepsilon$ were employed $(k-\varepsilon$ model). The $k-\varepsilon$ double equation model introduces a turbulent dissipation ratio $\varepsilon$ based on single equation model, which was firstly presented by Launder and Spalding in 1972 (Launder \& Spalding, 1972).

Turbulent kinetic energy $k$ equation is:

$$
\frac{\partial k}{\partial t}+\frac{\partial\left(\overline{u_{j}} k\right)}{\partial x_{j}}=\frac{1}{\rho} \frac{\partial}{\partial x_{j}}\left|\left[\mu+\frac{\mu_{t}}{\sigma_{k}}\right] \frac{\partial k}{\partial x_{j}}\right|+\frac{\mu_{t}}{\rho}\left[\frac{\partial \overline{u_{l}}}{\partial x_{j}}+\frac{\partial \overline{u_{j}}}{\partial x_{i}}\right] \frac{\partial U_{j}}{\partial x_{i}}-\varepsilon
$$

Turbulent dissipation ratio $\varepsilon$ equation is:

$$
\frac{\partial \varepsilon}{\partial t}+\frac{\partial\left(\overline{u_{j}} \varepsilon\right)}{\partial x_{j}}=\frac{1}{\rho} \frac{\partial}{\partial x_{j}}\left|\left[\mu+\frac{\mu_{t}}{\sigma_{\varepsilon}}\right] \frac{\partial \varepsilon}{\partial x_{j}}\right|+\frac{c_{1} \mu_{t} \varepsilon}{k}\left[\frac{\partial \overline{u_{l}}}{\partial x_{j}}+\frac{\partial \overline{u_{j}}}{\partial x_{i}}\right] \frac{\partial U_{j}}{\partial x_{i}}-\frac{c_{2} \varepsilon^{2}}{k}
$$

Turbulent viscosity coefficient $\mu_{t}$ is:

$$
\mu_{t}=c_{\mu} \rho k^{2} / \varepsilon
$$

where, $k$ is turbulent kinetic energy, $\varepsilon$ is turbulent kinetic dissipation ratio, $\mu_{t}$ is dynamic flow viscosity coefficient; $c_{p}$ is die material specific heat, $\rho \overline{u_{l}} \bar{T}$ is turbulent heat flux; $c_{1}, c_{2}, c_{\mu}$, $\sigma_{k}, \sigma_{\varepsilon}$ are turbulent empirical parameters, which provided by Launder \& Spalding now as shown in Table 1. 


\begin{tabular}{|c|c|c|c|c|c|}
\hline Parameters & $c_{1}$ & $c_{2}$ & $c_{\mu}$ & $\sigma_{k}$ & $\sigma_{\varepsilon}$ \\
\hline Value & 1.44 & 4.92 & 0.09 & 1.00 & 1.30 \\
\hline
\end{tabular}

Table 1. The empirical coefficient about $k-\varepsilon$ model

The dynamic viscosity used in the mass and momentum equations was the sum of molecular viscosity and turbulent viscosity. The viscosity of semi-solid material has drastically changed in the mushy state that the liquid phase and the globular solid phase coexist in the semi-solid forming region. The dependency of viscosity on shear rate must be recognized to establish the rheology model of semi-solid material. The viscosity decreases as shear rate increases in semi-solid region. The rheological model in FLOW3D is Carreau model as follows:

$$
\eta=\eta_{\infty}+\left(\eta_{0}-\eta_{\infty}\right)\left(1+(\lambda \dot{\gamma})^{2}\right)^{(n-1) / 2}
$$

where $\eta_{0}$ is low shear rate viscosity (zero shear rate viscosity, g.s $/ \mathrm{cm}$ ), $\eta_{\infty}$ is the high shear rate viscosity (g.s/cm), $\lambda$ is the time constant and $n$ is the sensitivity exponent of material. If the exponent $n$ is 1 , this equation becomes Newtonian flow model.

\subsection{Geometric model and initial parameters}

Due to vertical (i.e. left-right) and horizontal (i.e. front-back) mid-plane symmetry, only a quarter of the DCT was modelled as the computation. The geometric model and mesh is shown in Fig.2. The fall head is kept no variable, and the pressure of the inlet is kept a constant at initial condition. The AZ91D magnesium alloy was performed in this simulation, and its thermo-physical properties are presented in Table 2.

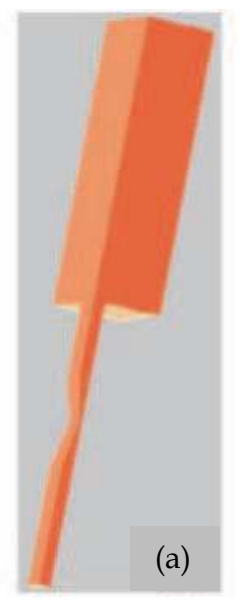

(a) geometry

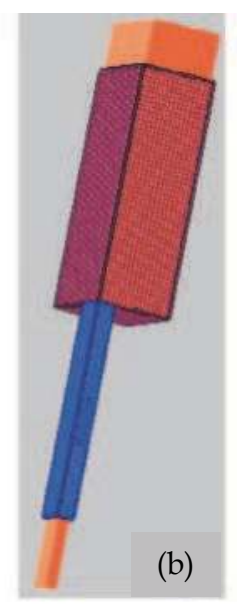

(b) mesh

Fig. 2. Geometry and mesh of the DCT 


\begin{tabular}{|l|c|c|}
\hline Parameters & Unit & Values \\
\hline Temperature at Liquidus & $\mathrm{K}$ & 868 \\
\hline Temperature at Solidus & $\mathrm{K}$ & 743 \\
\hline Specific heat & $\mathrm{KJ} / \mathrm{Kg} \cdot \mathrm{K}$ & 1050 \\
\hline Density & $\mathrm{Kg} / \mathrm{m}^{3}$ & 1810 \\
\hline Latent heat & $\mathrm{KJ} / \mathrm{Kg}$ & 373 \\
\hline Heat transfer coefficient & $\mathrm{W} / \mathrm{m}^{2} . \mathrm{K}$ & 104 \\
\hline
\end{tabular}

Table 2. The thermal-physical properties for AZ91D magnesium alloy

\subsection{Boundary conditions}

There are four boundaries specified in this DCT model. One boundary is the inlet surface which the molten alloy is poured into the container. The molten alloy temperature is $880 \mathrm{~K}$ above several degrees of the liquidus. The second boundary is the interface between the stationary wall of the container and the liquid alloy. The molten alloy temperature in the container is kept no variable, so the wall temperature of the container equal to the molten alloy temperature. The third boundary is the interface between the wall of the cooling tube and the molten alloy. The wall temperature of the cooling tube is room temperature $300 \mathrm{~K}$. The fourth boundary is the outlet boundary in the bottom.

\subsection{Numerical simulation results and discussion}

Fig.3 shows that the distribution of temperature, dynamic viscosity, shearing rate, velocity and solid fraction when the wedge block located in the middle of the cooling tube. It was found when the molten alloy passed through the wedge block, its temperature decreased highly from $880 \mathrm{~K}$ to $842 \mathrm{~K}$ under the cooling process of the tube and the stirring of wedge block; its dynamic viscosity increased quickly from 0.24 to $8.66 P$; its shearing rate increased from 0 to $1840 \mathrm{~s}^{-1}$; the velocity of molten alloy increased from 1.29 to $12 \mathrm{~m} / \mathrm{s}$; and the solid volume fraction increased from 0 to $5 \%$.

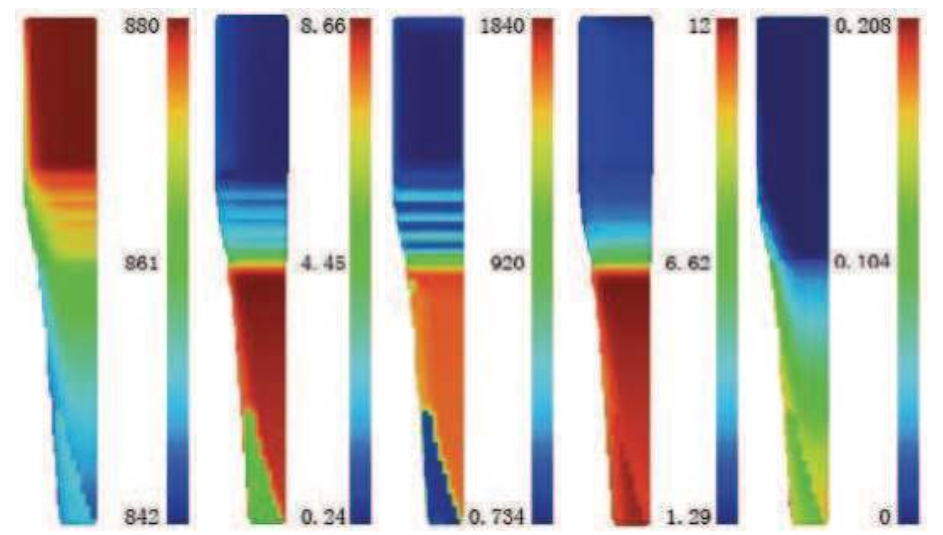

(a) temperature $(K)$; (b)dynamic viscosity $(P)$; (c) shearing rate $\left(\mathrm{s}^{-1}\right)$; (d) velocity $(\mathrm{m} / \mathrm{s})$; (e) solid fraction

Fig. 3. Simulation results when wedge block in the middle of the damper tube 
In addition, the fluid velocity near the outlet has a local variation because the tube wall cools continually, as shown in Fig.3 (d). It can also be seen that the flow field distribution is nonuniform at outlet. After the molten alloy flow passes the wedge block, it is still cooled by the tube but have no stirring. That is the reason that solid fraction is non-uniform at outlet and the slurry is not uniform at outlet.

Base on the above simulation results, we change the position of wedge block from middle to the outlet of the cooling tube while other parameters are the same. The simulation results are shown in Fig.4, it can be seen that the distribution of temperature, dynamic viscosity, shearing rate, velocity and solid fraction is more uniform. The shearing rate is up to the biggest value about $1860 \mathrm{~s}^{-1}$ at the gap. It shows that the wedge block has the perfect stirring in the process. The solid volume fraction of slurry is about $10 \%$ at outlet. The mixture of the semi-solid slurry is more homogeneous, which indicates that the wedge block plays good role in stirring the slurry. So, the wedge block should be located near outlet of the damper tube.
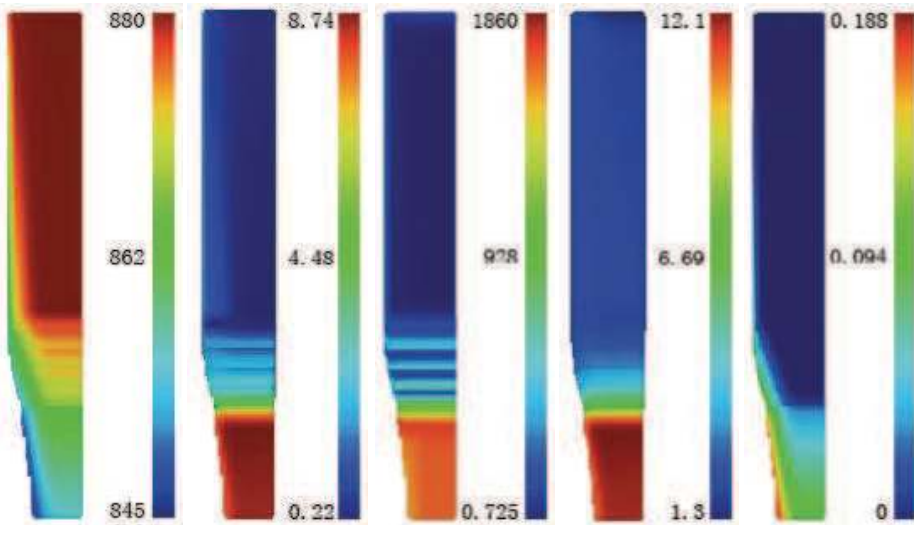

(a) temperature $(K)$; (b) dynamic viscosity $(P)$; (c) shearing rate $\left(s^{-1}\right)$; (d) velocity $(m / s)$; (e) solid fraction

Fig. 4. Simulation results when wedge block at outlet of the damper tube

Fig. 5 shows the temperature distribution at different gap size between the wedge block and the inner wall of cooling tube. It can be seen that the temperature distribution below the gap size is more uniform gradually with increasing the gap size from $2 \mathrm{~mm}$ to $10 \mathrm{~mm}$. The molten alloy flow per unit time through the gap increases with increasing the gap size, so mean cooling intensity of the cooling tube to the molten alloy decreases, which leads to the uniform temperature distribution below the wedge block. In addition, with increasing the gap size, the temperature gradient at the inclined surface of wedge block clearly increases for the friction between the molten alloy and inclined surface of the wedge block.

Fig. 6 shows the dynamic viscosity distribution for different gap size from $2 \mathrm{~mm}$ to $10 \mathrm{~mm}$. It can be seen that the dynamic viscosity in a local area at the cooling tube outlet is higher when the gap size is 2 and $4 \mathrm{~mm}$. When the gap size is greater than $8 \mathrm{~mm}$, the dynamic viscosity at the side surface of the cooling tube is higher than the center. Only when the gap size is $6 \mathrm{~mm}$, the dynamic viscosity below the gap size is more uniform. The variation of mean dynamic viscosity is shown in Fig.7. It can be seen that with increasing the gap size, the mean dynamic viscosity first gradually increases and then decreases. When the gap size is $6 \mathrm{~mm}$, the dynamic viscosity is up to maximum about $9.86 \mathrm{P}$. 

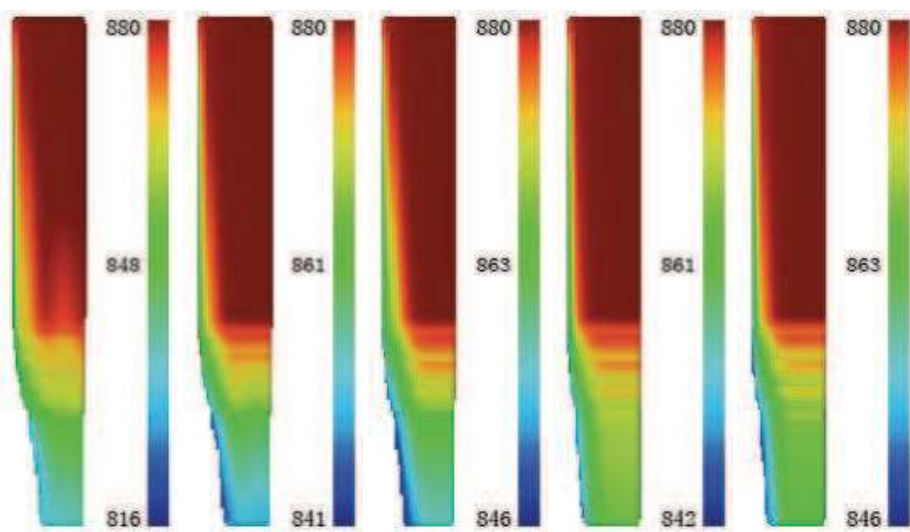

(a) $2 \mathrm{~mm}$

(b) $4 \mathrm{~mm}$

(c) $6 \mathrm{~mm}$

(d) $8 \mathrm{~mm}$

(e) $10 \mathrm{~mm}$

Fig. 5. Temperature distribution for different gap size $(K)$

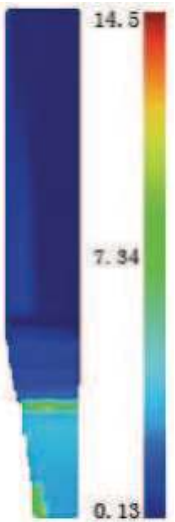

(a) $2 \mathrm{~mm}$

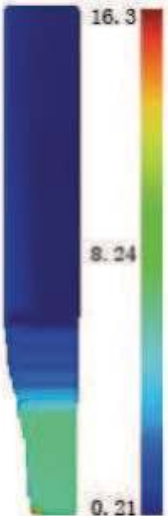

(b) $4 \mathrm{~mm}$

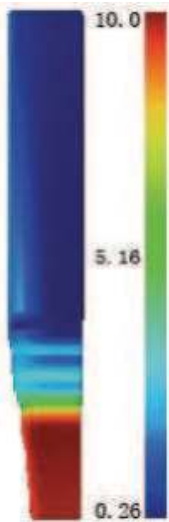

(c) $6 \mathrm{~mm}$

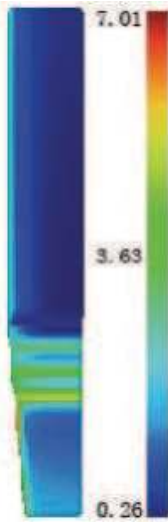

(d) $8 \mathrm{~mm}$

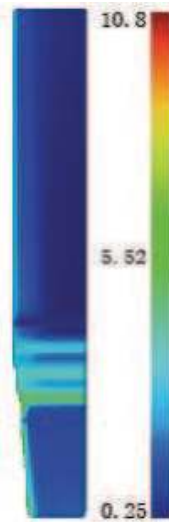

(e) $10 \mathrm{~mm}$

Fig. 6. Dynamic viscosity distribution for different gap size $(P)$

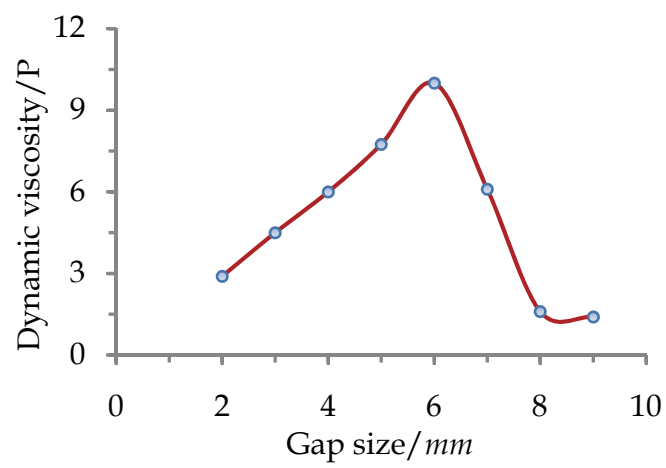

Fig. 7. Variation of dynamic viscosity for different gap size 
Fig. 8 and Fig.9 shows the distribution and variation of shearing rate in the cooling tube for different gap size. It can be seen that the gap size has great influence on the shearing rate distribution, too small or too large gap size will lead to lower shearing rate below the gap and almost close to zero. Only when the gap size ranges from 4 and $6 \mathrm{~mm}$, the shearing rate is higher about $1550 \mathrm{~s}^{-1}$, which indicates that the optimum gap size should be between $4 \mathrm{~mm}$ and $6 \mathrm{~mm}$.

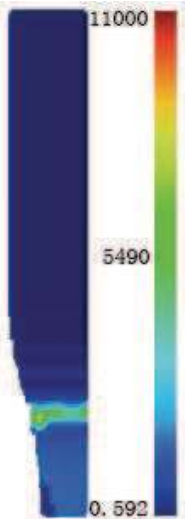

(a) $2 m m$

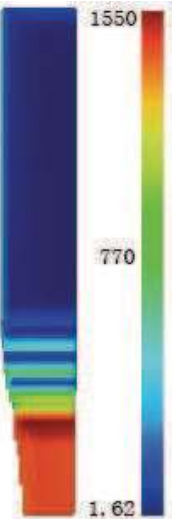

(b) $4 \mathrm{~mm}$

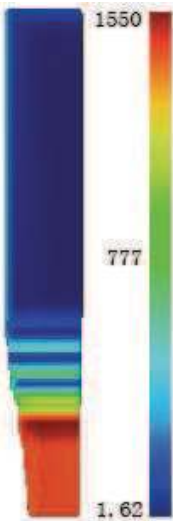

(c) $6 \mathrm{~mm}$

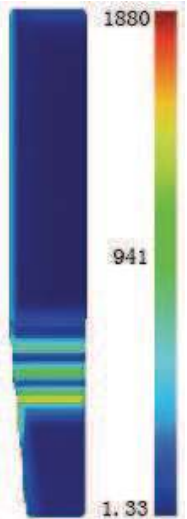

(d) $8 \mathrm{~mm}$

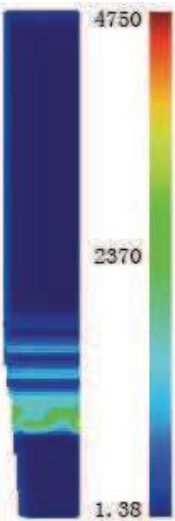

(e) $10 \mathrm{~mm}$

Fig. 8. Shearing rate distribution for different gap size $\left(s^{-1}\right)$

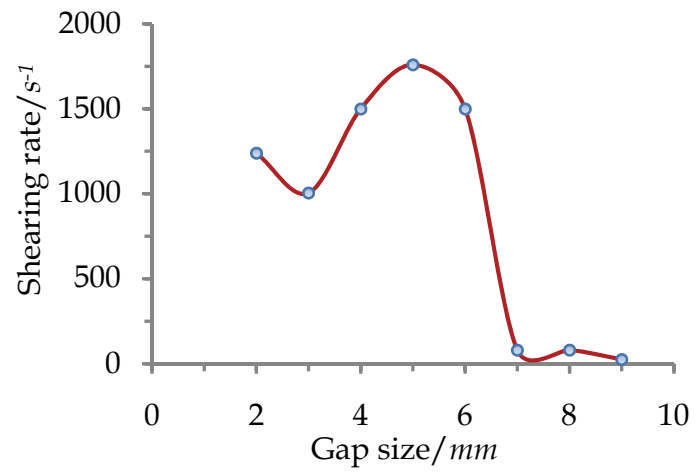

Fig. 9. Variation of shearing rate for different gap size

The velocity distribution for different gap size is shown in Fig.10. It can be seen that the local metal flow velocity below the gap in cooling tube is non-uniform when the gap size is too large and too small. When the gap size increases from 4 to $8 \mathrm{~mm}$, the metal flow velocity distribution is more uniform and little difference each other, about $1.18 \mathrm{~m} / \mathrm{s}$.

Fig.11 and Fig.12 shows the distribution and variation of solid fraction for different gap size. It can be seen that with increasing the gap size, the solid fraction distribution is more nonuniform, and the solid fraction gradually decreases, which indicates the gap size has great effect on the solid fraction. When the gap size is beyond $7 \mathrm{~mm}$, the solid fraction of the molten alloy in then cooling tube is close to zero as show in Fig.12. So, the gap size must be less than $7 \mathrm{~mm}$. 

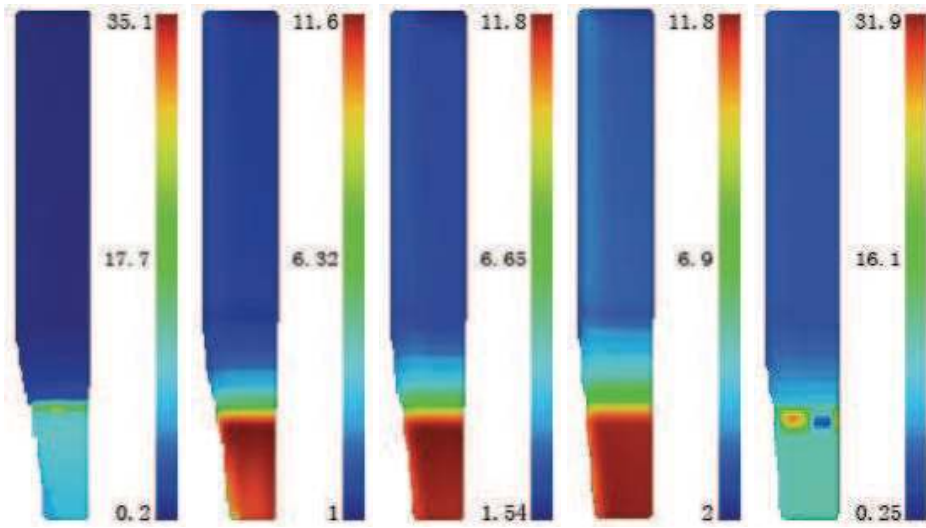

(a) $2 \mathrm{~mm}$

(b) $4 \mathrm{~mm}$

(c) $6 \mathrm{~mm}$

(d) $8 \mathrm{~mm}$

(e) $10 \mathrm{~mm}$

Fig. 10. Velocity distribution for different gap size $(\mathrm{m} / \mathrm{s})$

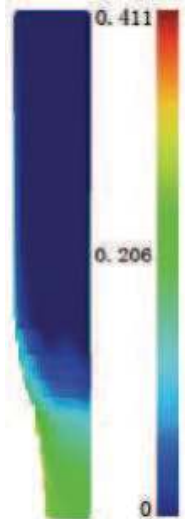

(a) $2 \mathrm{~mm}$

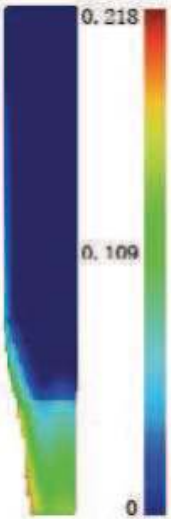

(b) $4 \mathrm{~mm}$

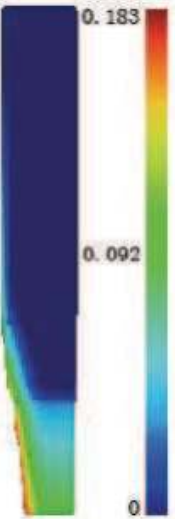

(c) $6 \mathrm{~mm}$

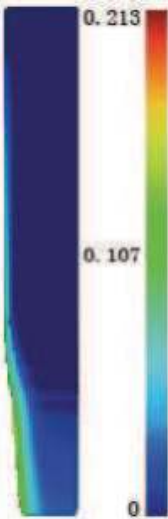

(d) $8 \mathrm{~mm}$

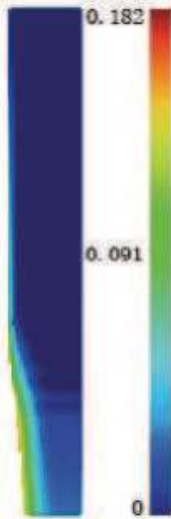

(e) $10 \mathrm{~mm}$

Fig. 11. Solid fraction distribution for different gap size

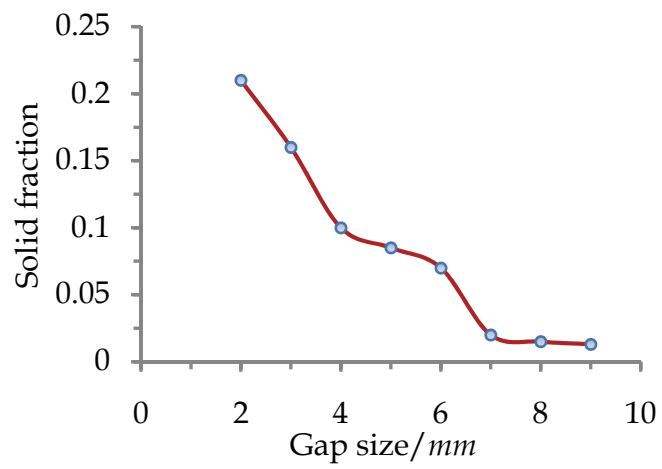

Fig. 12. Variation of solid fraction for different gap size 
Because the fall head of the molten alloy in the container is the driving force of the flowing of molten alloy, the fall head is an important factor in the process, the effect of fall head is analyzed. The varieties of the temperature and shearing rate with fall head from $50 \mathrm{~mm}$ to $700 \mathrm{~mm}$ are shown in Fig.13 and Fig.14. Fig.13 shows that the fall head have a little effect on the temperature distribution. Fig.14 shows that the shearing rate is non-uniform when the fall heat was below $300 \mathrm{~mm}$. But when the fall head is higher than $500 \mathrm{~mm}$, the distribution of shearing rate is uniform and has little change. So the fall head must be higher than $500 \mathrm{~mm}$ to get the better stirring function.

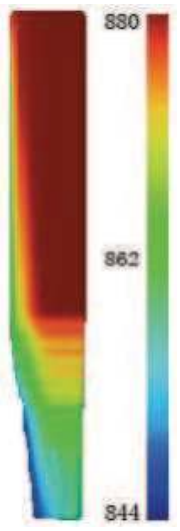

(a) $50 \mathrm{~mm}$

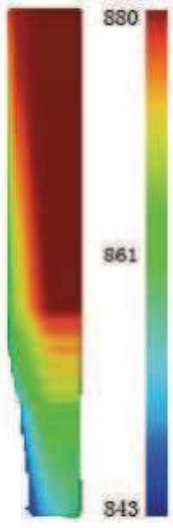

(b) $100 \mathrm{~mm}$

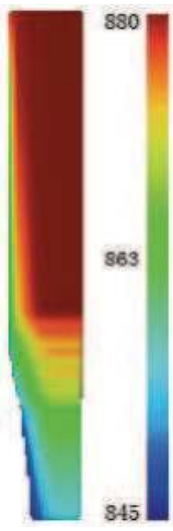

(c) $300 \mathrm{~mm}$

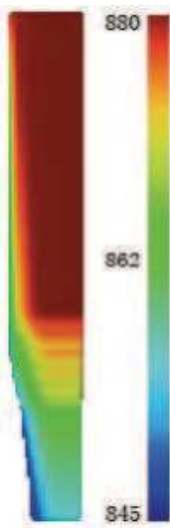

(d) $500 \mathrm{~mm}$

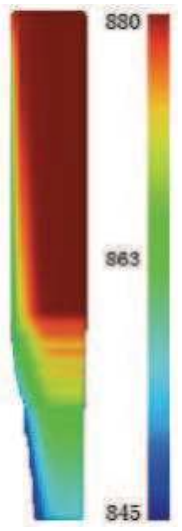

(e) $700 \mathrm{~mm}$

Fig. 13. Temperature distribution for different fall height $(K)$

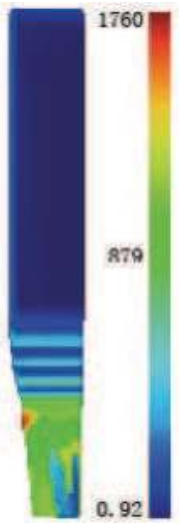

(a) $50 \mathrm{~mm}$

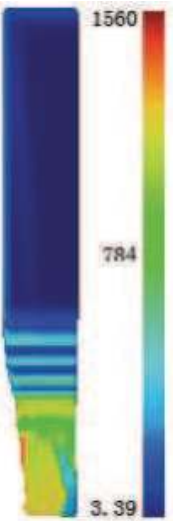

(b) $100 \mathrm{~mm}$

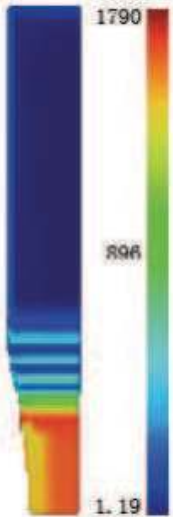

(c) $300 \mathrm{~mm}$

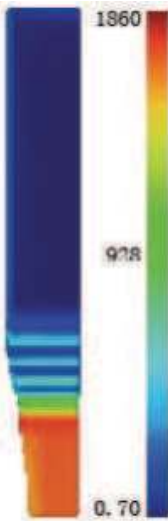

(d) $500 \mathrm{~mm}$

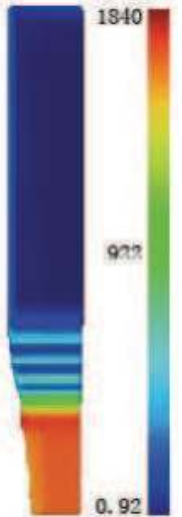

(e) $700 \mathrm{~mm}$

Fig. 14. Shearing rate distribution for different fall height $\left(s^{-1}\right)$

The temperature distribution at different height of wedge block from $60 \mathrm{~mm}$ to $140 \mathrm{~mm}$ (the fall head is $500 \mathrm{~mm}$ ) are shown in Fig.15. It was shown that the height of wedge block has little effect on the temperature distribution. The temperature at outlet is about $855 \mathrm{~K}$. The temperature of the left tube wall is lower, about $845 \mathrm{~K}$. So, it can be concluded that the height of wedge block has little influence on the temperature distribution. 


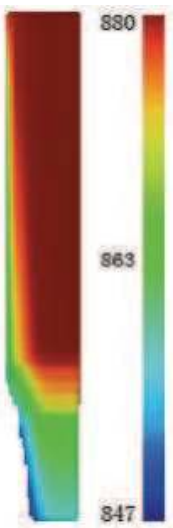

(a) $60 \mathrm{~mm}$

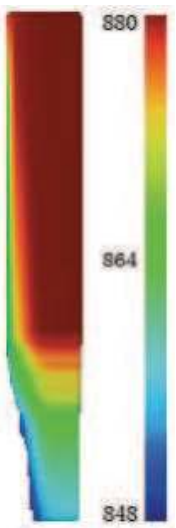

(b) $80 \mathrm{~mm}$

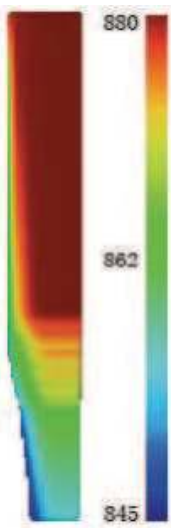

(c) $100 \mathrm{~mm}$

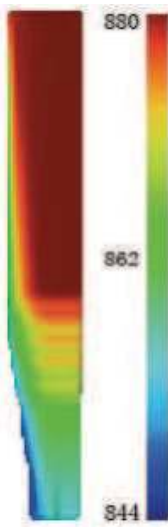

(d) $120 \mathrm{~mm}$

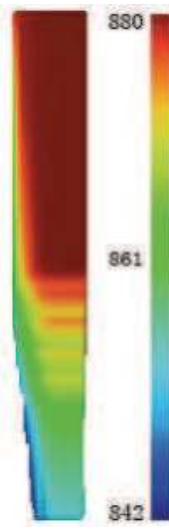

(e) $140 \mathrm{~mm}$

Fig. 13. Temperature distribution for different height of wedge block $(K)$

\subsection{Experimental research on DCT}

The experimental device of DCT for preparing the semi-solid magnesium alloys slurry was designed and fabricated as shown in Fig.14. According the numerical simulation results, the wedge block was set near the outlet of cooling tube; the height of wedge block was $100 \mathrm{~mm}$. The fall head was 300, 500 and $700 \mathrm{~mm}$ respectively.

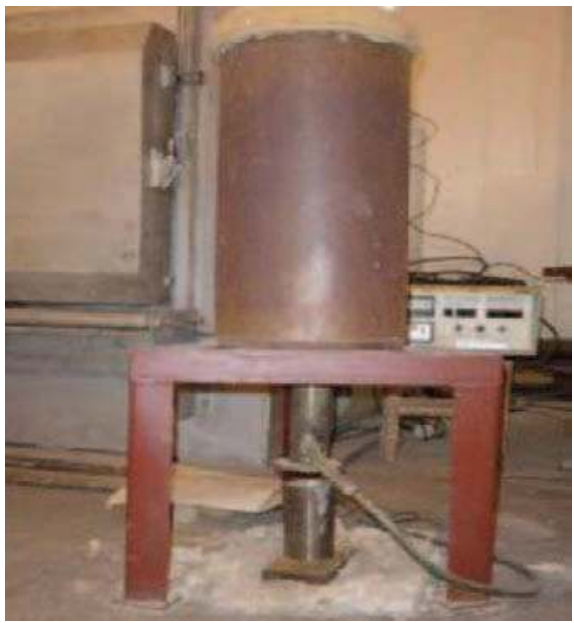

Fig. 14. Experimental device of DCT

AZ91D magnesium was used in this experiment. The smelting device was an electric resistance furnace with controllable silicon power $(20 \mathrm{KW})$. Other relative devices contained a controllable silicon power, a set of thermo detector and recording instrument, a set of casting device, a group of stainless steel mould and ten groups of sand moulds. And the smelting process was protected using Argon gas. Detailed experimental condition was shown in Table 3. 


\begin{tabular}{|l|l|}
\hline Material & AZ91D magnesium alloy \\
\hline Casting temperature $/ \mathrm{K}$ & 880 \\
\hline Smelting device & $20 \mathrm{Kg}$ Electric resistance furnace \\
\hline Shielding gas & Argon \\
\hline Casting mould & Stainless steel mould \\
\hline DCT device & Designed by oneself \\
\hline The location of wedge block & Outlet of cooling tube \\
\hline The height of wedge block $/ \mathrm{mm}$ & 100 \\
\hline The height of fall head $/ \mathrm{mm}$ & $300,500,700$ \\
\hline
\end{tabular}

Table 3. The experimental condition
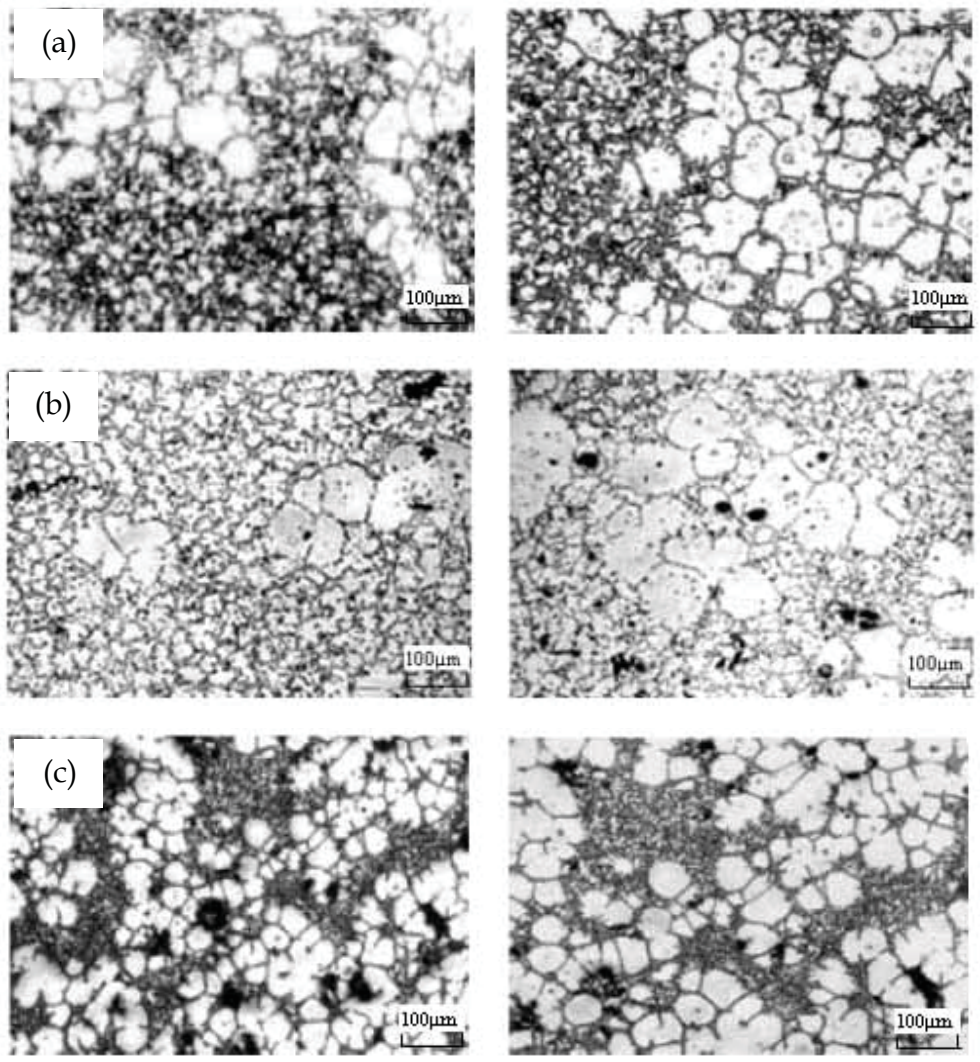

a) edge

b) centre

Fig. 15. The microstructure with the different fall head (a) 300 $\mathrm{mm}$; (b) $500 \mathrm{~mm}$; (c) $700 \mathrm{~mm}$

The edge and centre microstructure of billets using the DCT device are shown in Fig.15. It is shown that the microstructure is non-uniform when the fall head is $300 \mathrm{~mm}$ in Fig.15 (a). When the fall head is $500 \mathrm{~mm}$, the microstructure is better than the $300 \mathrm{~mm}$, but there are many big grains in the centre of the billets as shown in Fig.15 (b). Fig.15 (c) shows that the 
microstructure is more uniform and thinner when the fall head is $700 \mathrm{~mm}$. From the experiment it can be concluded that the height of wedge block should be located near outlet of the damper tube and it was not the main influence factor to the temperature distribution. The fall head must be higher than $500 \mathrm{~mm}$ to get the better stirring function. The fall head must be higher than $500 \mathrm{~mm}$ for getting better microstructure, which is in accord with the numerical simulation results.

\section{Semi-solid continuous roll-casting processing}

In semi-solid continuous roll-casting process of magnesium alloy, several processing parameters such as the solid fraction of semi-solid slurry, the heat transfer between rollers and molten alloy, the roll-casting speed, the position of solidification final point have great influence on the quality of final strips (Xie et al, 2005, 2006, 2007and 2008; Zhang et al, 2008). So, in this section numerical simulation on semi-solid continuous roll-casting process of magnesium alloy using a two-dimensional incompressible non-Newtonian flow model was studied for getting the optimizing processing parameters. Based on the simulation results, semi-solid continuous roll-casting process experiment for AZ91D magnesium alloy were investigated.

\subsection{Mathematical modeling}

\section{Governing equations}

The continuity equation is:

$$
\frac{\partial \rho}{\partial t}+\frac{\partial\left(\rho u_{i}\right)}{\partial x_{i}}=0
$$

The Navier-Stokes equation is:

$$
\frac{\partial\left(\rho u_{i}\right)}{\partial t}+\frac{\partial}{\partial x_{j}}\left(\rho u_{j} u_{i}+P \delta_{i j}-\sigma_{i j}\right)=\rho g_{i}
$$

The energy equation is:

$$
\rho c \frac{\partial T}{\partial t}-\lambda \frac{\partial^{2} T}{\partial x_{i}^{2}}-q(x)=0
$$

where $\rho$ is the density, $u_{i}$ is the velocity of element $i, x_{i}$ is the displacement of element $i, P$ is the pressure, $\delta_{i j}$ is the Kronecker delta function, $\sigma_{i j}$ is the viscosity tension between element $i$ and $j, g_{i}$ is the gravity acceleration of element $i, c$ is the specific heat, $T$ is the temperature, $\lambda$ is the thermal conductivity coefficient and $q(x)$ is the thermal source.

These equations were solved by the FLOW3D software for a steady-state solution. In FLOW3D, the above equations are formulated with the Fractional Area/Volume Obstacle Representation (FAVOR) method. In addition, the non-Newtonian viscosity model is used by eq.(4).

\section{Solidification latent heat}

The solidification process of semi-solid continuous roll-casting processing is an unsteady state heat transfer process with phase transformation. Semi-solid slurry can release mass crystallization latent heat from solid-liquid mixing to pure solid phase. At present, there are many methods, such as temperature compensation method, effective specific heat method, 
heat content method, assumption heat flow method and so on, for dealing with the crystallization latent heat. The heat content method was used in this chapter, namely, the crystallization latent heat was defined as follow:

$$
H=\int \rho C_{p}(T) d T
$$

where, $H$ is material heat content, $\rho$ is material density; $C_{p}$ is material specific heat capacity, which is the function of temperature $T$.

\section{Geometry and parameters}

Applying simple geometric mode was a good way to get some progress in study. So, some assumption condition was made before establishing the analysis model: 1) steady-state rollcasting process; 2) no relative slip between semi-solid slurry and semi-solid magnesium strips and rollers; 3 ) well contact between strips and rollers, thus ignoring thermal resistance between them. In semi-solid continuous roll-casting process, the molten pool was enclosed by two water cooling rollers and side plate. The width of water slot was nearly equal to the roller width and thermal insulation device and heated side plate was used, so the edge effect of casting strips can be ignored. The two-dimensional geometric model and mesh was built after simplifying the semi-solid continuous roll-casting process as shown in Fig.16. The detailed calculation parameters in numerical simulation were shown in Table 4.

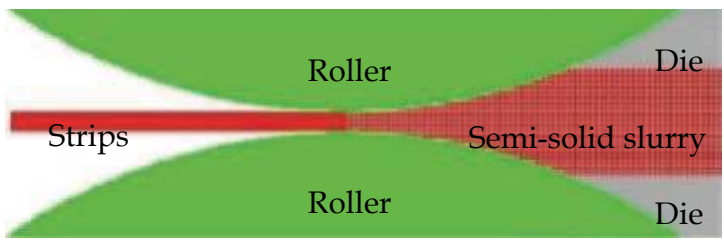

Fig.16. The 2D model and mesh of semi-solid continuous roll-casting process

\begin{tabular}{|c|c|c|c|c|}
\hline Roll-casting speed & Roll diameter & Pool depth & Roll gap & Inlet temperature \\
\hline $0.6-1.2 \mathrm{~m} / \mathrm{min}$ & $210 \mathrm{~mm}$ & $30-50 \mathrm{~mm}$ & $4 \mathrm{~mm}$ & $840-860 \mathrm{~K}$ \\
\hline$V$ & $D$ & $h$ & $\delta$ & $T_{0}$ \\
\hline
\end{tabular}

Table 4. The detailed calculation parameters in numerical simulation

\section{Boundary condition}

The governing equations must satisfy every surface's boundary condition in calculation zone, which mainly contains velocity and thermal boundary condition. The boundary condition descriptions in this study are as follows:

Inlet zone:

$$
V_{x}=V_{\text {in }}, V_{y}=0, T=T_{0}
$$

where $V_{x}$ is the node velocity at $x$ direction in the inlet position of molten pools, $V_{y}$ is the node velocity at $y$ direction in the inlet position of molten pools, $V_{i n}$ is the velocity of molten alloy in the let position, $T_{0}$ is the casting temperature.

Free surface:

$$
V_{y}=0, \frac{\partial V_{x}}{\partial y}=0, \frac{\partial V_{z}}{\partial y}=0
$$


The contact surface between molten alloy and roller:

In continuous roll-casting process, the viscosity force near the roller surface zone plays important role in transportation, so the velocity of element nodes contacted with the roller surface is defined as the linear velocity of roller, namely, the element node velocity is:

$$
V_{x}=V \operatorname{Cos} \theta, V_{y}=V \operatorname{Sin} \theta, \mathrm{z}=0
$$

where, $V$ is the linear velocity of rollers surface, $\theta$ is the angle from the line between node and axis line of rollers to $x-z$ plate.

\subsection{Numerical simulation results and analysis}

At beginning continuous roll-casting process the inlet velocity of slurry $V_{0}$ is $0.05 \mathrm{~m} / \mathrm{min}$; the roll gap $\delta$ is $4 \mathrm{~mm}$; pool depth $h$ is $20 \mathrm{~mm}$; the roll-casting velocity is $1 \mathrm{~m} / \mathrm{min}$. The AZ91D semisolid slurry firstly was poured into the right molten pool in the simulation, at this time, the effect of rollers temperature was ignored. When the flow field of roll-casting zone was up to steady state, the boundary condition of roller temperature was set, thus, the semi-solid slurry started to solidify under the rollers cooling. Lastly, the distribution of temperature and solid fraction at continuous casting zone was obtained.

\subsubsection{The distribution of temperature and solid fraction at roll-casting zone}

Based on the experience and experiment, the solid fraction of initial semi-solid slurry has been selected $10 \sim 20 \%$ in CRP. It is known that the solid fraction of semi-solid slurry corresponding to the temperature, thus the temperature of semi-solid slurry has been selected from $840 \mathrm{~K}$ to $860 \mathrm{~K}$. In this study, the inlet temperature of molten alloys $T_{0}$ is $855 \mathrm{~K}$. Fig.17 shows the changing of the temperature and solid fraction at roll-casting zone, when the rollers cooling time is $0.5,1.0,1.5,2.0,2.5 s$, respectively.

When the cooling time was $0.5 \mathrm{~s}$, the temperature of molten alloy near the rollers dropped down about $800 \mathrm{~K}$ rapidly due to the high temperature difference between the molten alloy and the water cooled rollers. Here, the solid fraction of the molten alloy at the rollers surface increased by $70 \%$, but no solidification layer. As shown in Fig. 17 when the cooling time was $1.0 \mathrm{~s}$, the temperature of molten alloy near the rollers continuously down to about $742 \mathrm{~K}$, and the solid fraction also increased. At this time the thin solidified layer formed at rollers surface contacted with the molten alloy, and the thickness of the solidified layer was about $0.2 \mathrm{~mm}$ at minimum roll gap. When the cooling time was $1.5 \mathrm{~s}$, the temperature of molten alloy decreased about $700 \mathrm{~K}$ and the thickness of solidified layer was about $0.5 \mathrm{~mm}$. The solidified layers, however, were not jointed together due to the roll gap was $4 \mathrm{~mm}$. So, the thickness must be up to $2 \mathrm{~mm}$, two solidified layers can contact and press together. With the decreasing the temperature of molten alloy, the thickness of solidified layers increased and the two layers had contacted each other when the cooling time was 2.0s. When the cooling time was 2.5s, the temperature of molten alloy near rollers surface had decreased into about $650 \mathrm{~K}$ as shown in Fig.10, the thickness of solidified layer had grown to more than $2 \mathrm{~mm}$ at the roll tip where two solidified layers contacted and welded together. From the solid fraction distribution, it was observed that the solidified layers welded to each other about 5 $\mathrm{mm}$ at the right of the roll tip which was the position of solidification final point. Therefore, the solidification in the roll gap was completed and ready for the following rolling operation. At this moment the solidified strip was withdrawn from the roll tip and had been rolled. According to the numerical simulation results, the roll-casting speed must be 
controlled strictly and the contact time between the rollers and strips must exceed $2.5 \mathrm{~s}$. It means that only when the roll-casting speed is lower than $1 \mathrm{~m} / \mathrm{min}$, the roll-casting strip can be solidification at roll gap and CRP can be finished successfully.

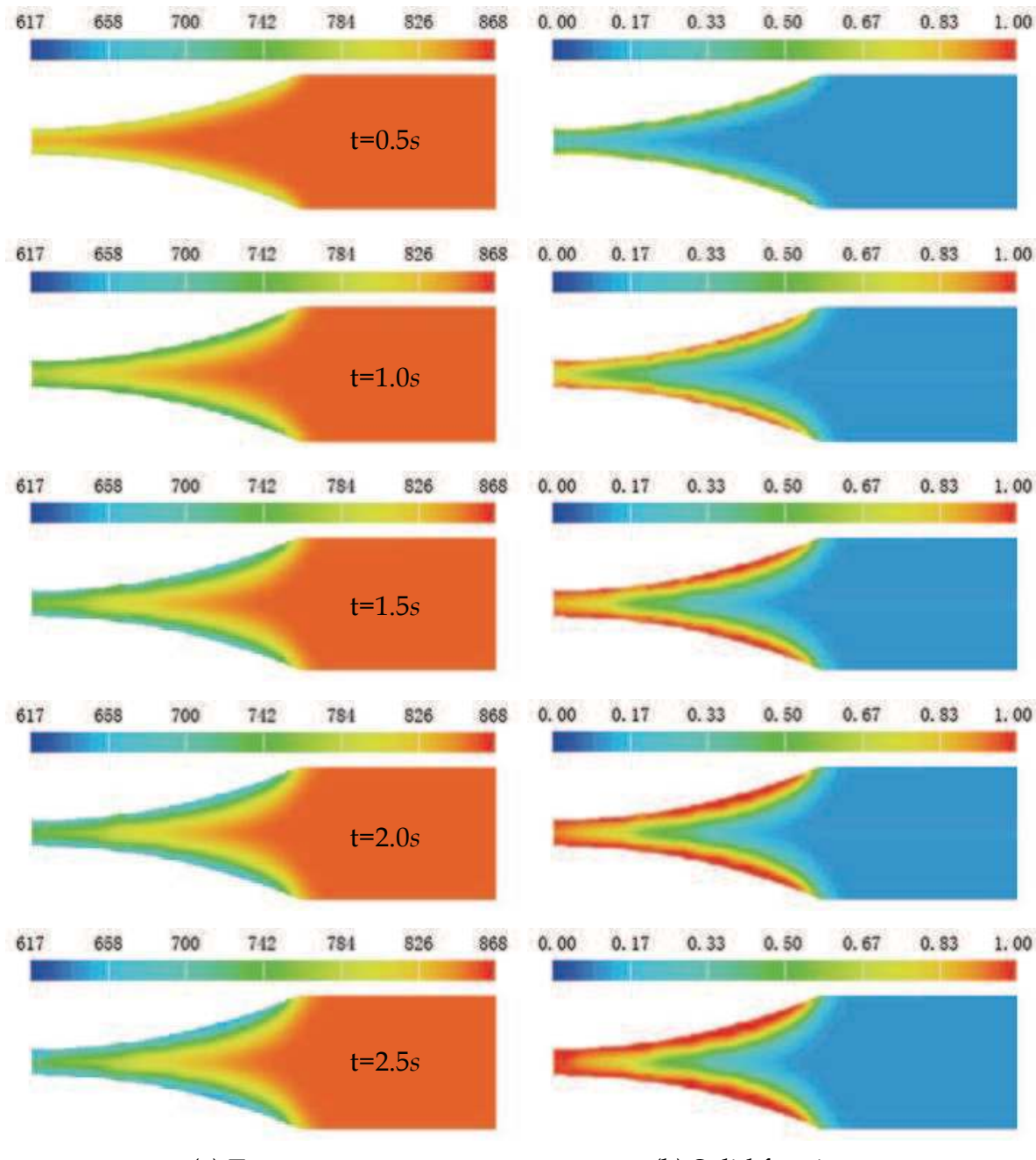

(a) Temperature

(b) Solid fraction

Fig. 17. Distribution of temperature and solid fraction at different roller cooling time

\subsubsection{Effect of pouring temperature on the CRP processing}

It is known that different pouring temperature of semi-solid slurry correspond to different solid volume fraction with unchanging other parameters, while the solid volume fraction can affect the flow and heat transfer ability of semi-solid slurry. Thus, the pouring temperature has great influence on the metal flow and heat transfer in molten pool. In this 
study, the temperature and solid volume fraction is assumed to be linear. Fig.18 shows the relation between the pouring temperature and solid fraction of semi-solid AZ91D alloy.

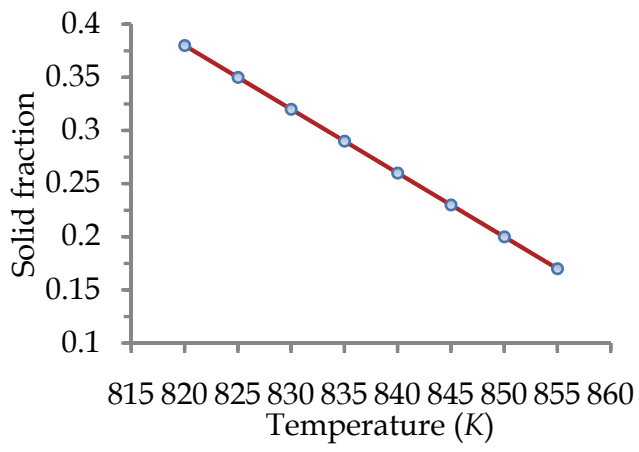

Fig. 18. Relation between pouring temperature and solid fraction of semi-solid AZ91D alloy

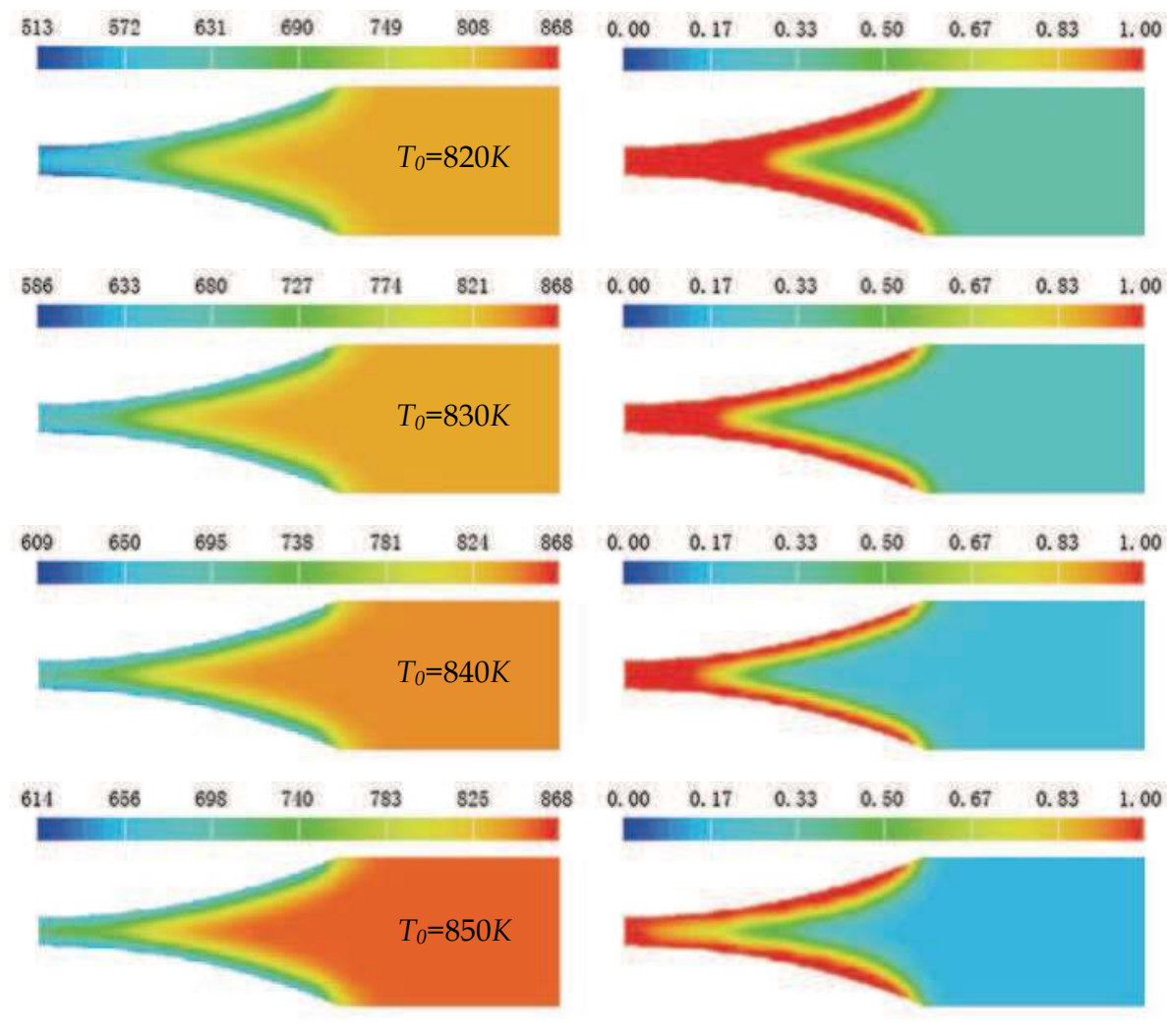

(a) Temperature

(b) Solid fraction

Fig. 19. Distribution of temperature and solid fraction at different pouring temperature 
Fig.19 shows the distribution of temperature and solid fraction in molten pool at different pouring temperature $820,830,840,850 K$, respectively. It is shown that when the pouring temperature is $820 \mathrm{~K}$, the position of solidification final point is near the right side for lower pouring temperature, and the length of rolling zone is about $21 \mathrm{~mm}$, which cause higher rollcasting load and is not benefit to CRP process. With increasing the pouring temperature, the length of rolling zone decreases continuously, the solidification final point move towards to the outlet of strips. As $T_{0}$ is $850 \mathrm{~K}$, the length of rolling zone is about $3 \mathrm{~mm}$.

It can be conclude that the pouring temperature has great influence on the temperature and solid fraction in molten pool and the solidification final point. With increasing the pouring temperature, the length of rolling zone decreases. Also the pouring temperature can affect the flow filed in molten pool. Lower pouring temperature increases the viscosity of slurry, which leads to bad flowing ability. In addition, lower pouring temperature easily results in higher roll-casting load. However, higher temperature makes short position of rolling zone, which leads to breaking of CRP for incompletely solidification of strips.

\subsubsection{Effect of roll-casting velocity on the CRP processing}

Roll-casting velocity plays important role in the CRP processing, rational velocity can keep the CRP stability. Higher roll-casting velocity will lead to insufficient solidification of molten alloy; Lower roll-casting velocity will lead to longer standing time of the molten alloy in roll-casting zone for excessive cooling, which makes the molten alloy solidify at casting lip and breaks the semi-solid continuous roll-casting process. In this part, different roll-casting velocities $0.6,0.8,1.0,1.2 \mathrm{~m} / \mathrm{min}$, respectively were studied when the depth of molten pool was $20 \mathrm{~mm}$, pouring temperature $T_{0}$ was $855 \mathrm{~K}$.

Fig.20 shows the distribution of temperature and solid fraction at different roll-casting velocities. It is shown that when the velocity $V$ is $0.6 \mathrm{~m} / \mathrm{min}$, the solidification final point is far from the outlet of strips, the length of rolling zone is about $17 \mathrm{~mm}$.With increasing the rollcasting velocity, the length of rolling zone decreases gradually. When the velocity is $1.2 \mathrm{~mm} / \mathrm{s}$, the length of rolling zone is only about $1 \mathrm{~mm}$. So, in practical roll-casting process, the proper velocity should be chosen according the specific condition, in order to guarantee the quality of strips.

\section{Experimental researches on the semi-solid CRP of magnesium alloy}

Semi-solid continuous roll-casting device was designed with the combination of semi-solid metal processing and horizontal double roll-casting technology. The CRP experiment of AZ91D and AZ31B (Zhang et al, 2007) was investigated for verifying the numerical simulation model and results of CRP. In addition, the further processability of semi-solid AZ91D and AZ31B strips by hot rolling, cold rolling and punching experiment was studied.

\subsection{Experimental procedures}

AZ91D and AZ31B alloy were melted in electrical resistance furnace, and modified at 1013K. Molten alloy was stirred below $868 \mathrm{~K}$ in the range of between liquid and solid phase, semisolid metal slurry was obtained, and then poured into the roll-casting machine. Fig.21 shows experimental equipment of the horizontal double roll-casting. Liquidus and solidus temperature of AZ91D alloy is $868 \mathrm{~K}$ and $743 \mathrm{~K}$ respectively. Chemical composition of AZ91D and AZ31B alloy are shown in Table 5. 

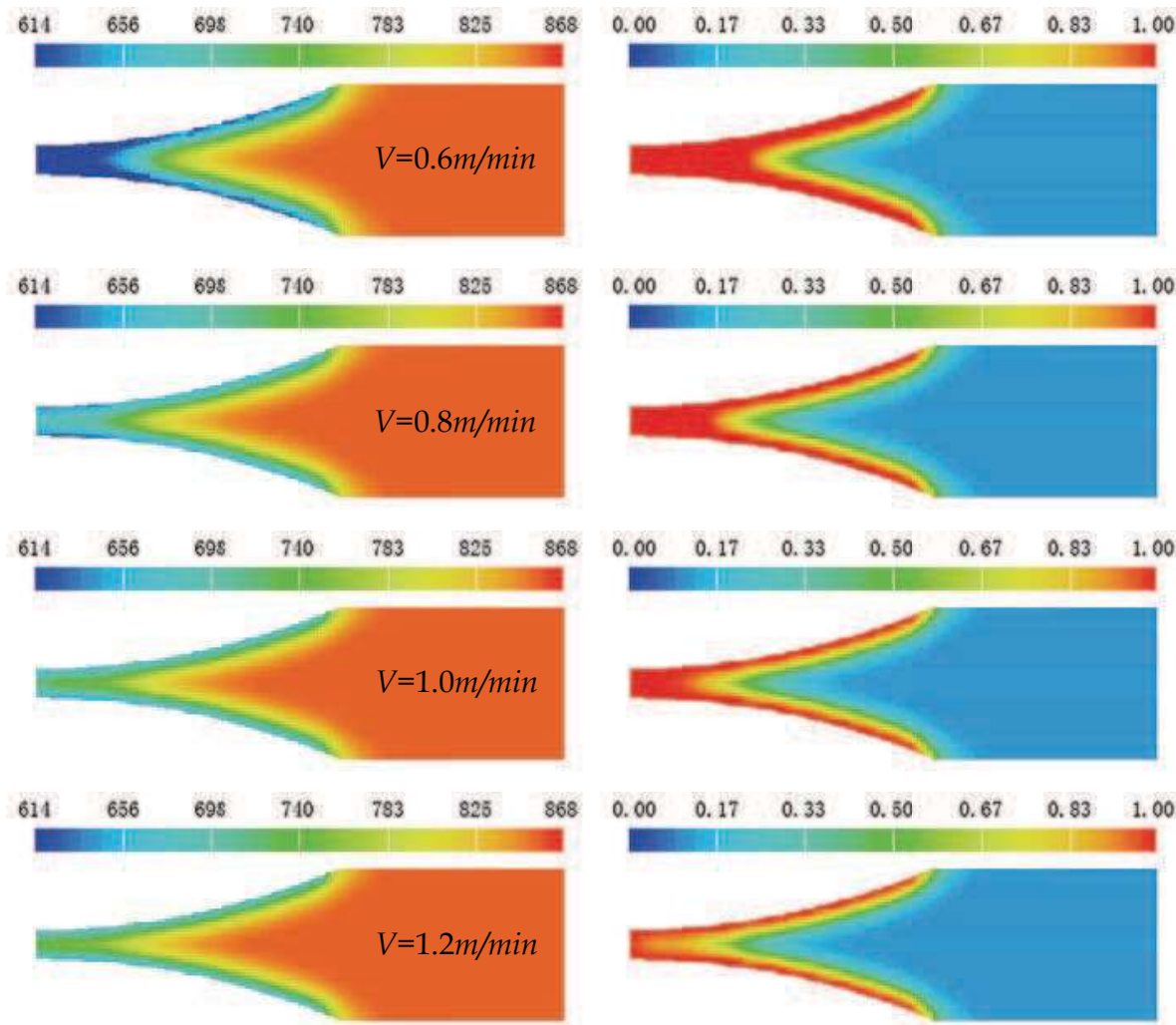

(a) Temperature
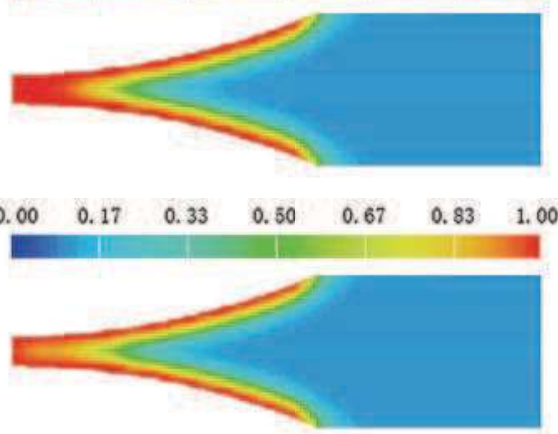

(b) Solid fraction

Fig. 20. Distribution of temperature and solid fraction at different roll-casting velocity

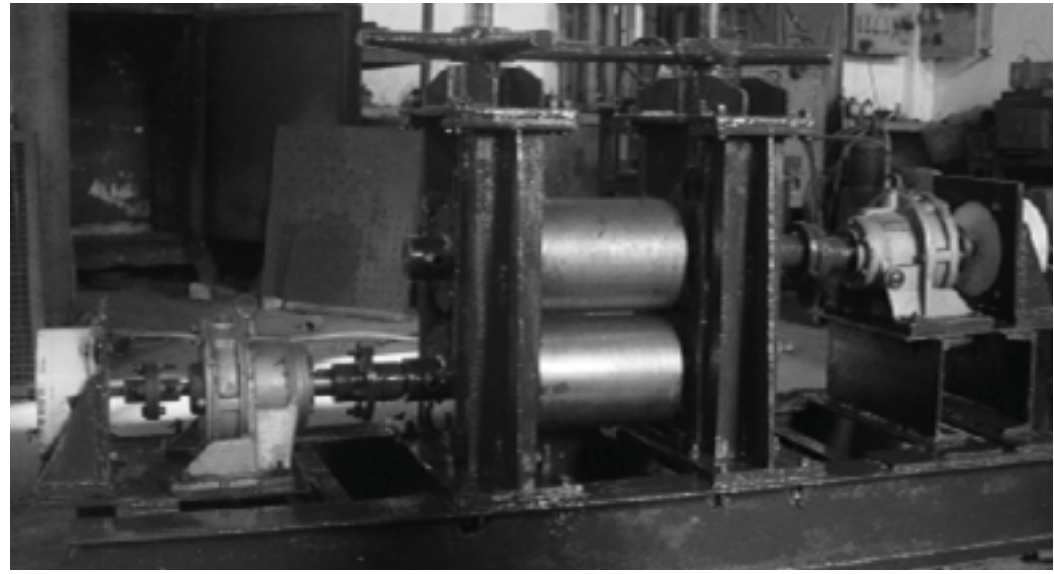

Fig. 21. The experimental equipment of horizontal double roll-casting 


\begin{tabular}{|c|c|c|c|c|c|c|c|c|c|}
\hline Alloy & $\mathrm{Al}$ & $\mathrm{Zn}$ & $\mathrm{Mn}$ & $\mathrm{Be}$ & $\mathrm{Si}$ & $\mathrm{Cu}$ & $\mathrm{Fe}$ & $\mathrm{Ni}$ & $\mathrm{Mg}$ \\
\hline AZ91D & $8.3-9.7$ & $0.35-1.0$ & $0.15-0.2$ & 0.0014 & 0.031 & 0.0049 & 0.0011 & 0.002 & Balance \\
\hline AZ31B & 2.946 & 0.992 & 0.3003 & 0.0014 & 0.0049 & 0.0028 & 0.0016 & 0.0003 & Balance \\
\hline
\end{tabular}

Table 5. Chemical composition of AZ91D and AZ31B magnesium alloy (wt\%)

\subsection{Experimental results and discussion}

One sample of before roll-casting and other sample of after roll-casting have been taken respectively. All samples were polished and etched by $5 \%$ hydrochloric acid reagent. And then its microstructure has been analyzed by the method of metallographic analysis, the microstructure compare of pre and pro roll-casting strip are shown in Fig.22. Here, the temperature of semi-solid metal slurry is $842 \mathrm{~K}, 838 \mathrm{~K}, 833 \mathrm{~K}$ respectively, the stirring speed is $516 \mathrm{rpm} / \mathrm{min}$ and stirring time is $5 \mathrm{~min}$. It can be seen that there is obvious diversity in the microstructure of before and after roll-casting strips, the microstructure of before rollcasting is clear polygonal primary crystal, but the microstructure of after roll-casting is globular and closely resembles globular crystal; and the roll-casting temperature has little influence on the final structure. So, higher semi-solid slurry temperature can be adopted in practical production, which is of great benefit to the distributary of the molten alloy.

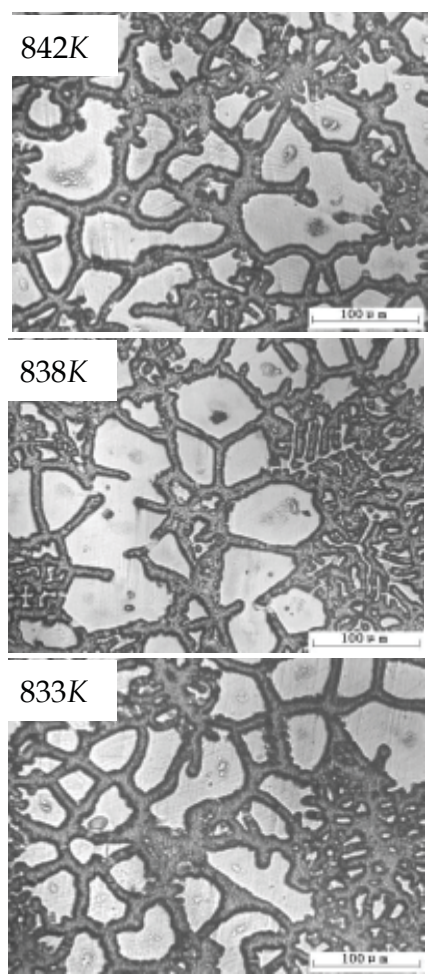

(a) Before roll-casting

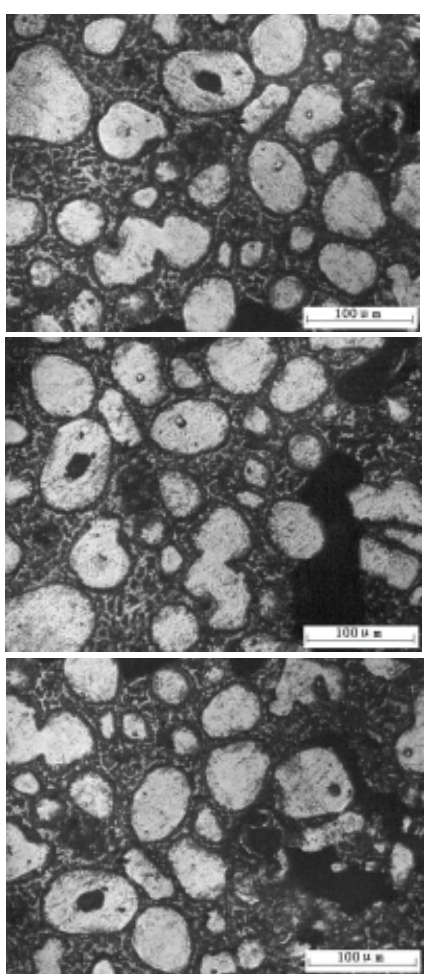

(b) After roll-casting

Fig. 22. The microstructure contrast of before and after roll-casting at different temperature 
The semi-solid magnesium roll-casting strips were obtained when the roll-casting temperature is $842 \mathrm{~K}$, stirring velocity is $516 \mathrm{rpm} / \mathrm{min}$ and stirring time is $5 \mathrm{~min}$. Fig.23 shows the microstructure of top surface, inner and bottom surface of the thick strips. It can be seen that surface microstructure is fine equiaxed grain for quickly cooling of rollers surface and the grain size of the surface is smaller than it of the inner. When the height of roll gap decreases and other processing parameters are invariable, the difference of primary solid particles in inner and surface also decreases. However, when the height of roll gap increases the difference of primary solid particles in inner and surface also increases.

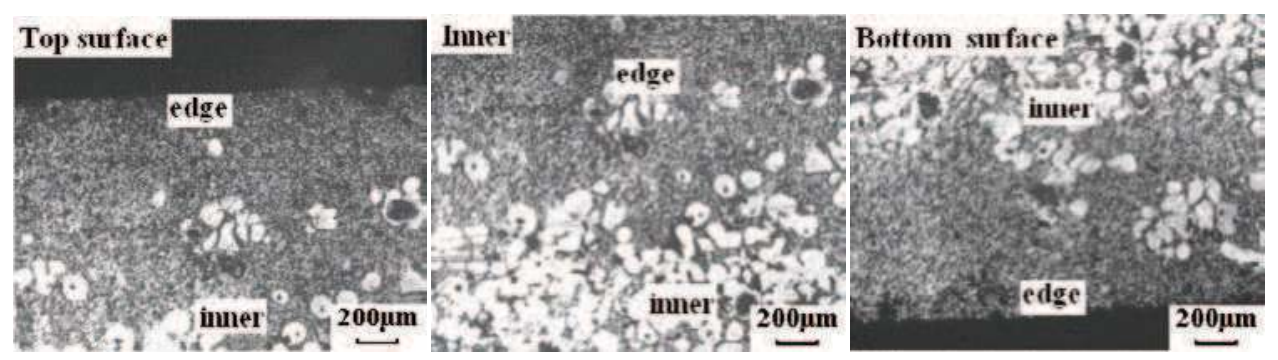

Fig. 23. Microstructure of top surface, inner and bottom surface of the thick strips

\subsection{Processing property test of semi-solid strips}

In order to examine the processing property of semi-solid AZ91D magnesium strips by CRP, hot-rolling and cold-rolling experiments were carried out respectively. The semi-solid rollcasting strips were tested under hot-rolling and cold-rolling, and the results were shown in Table 6. It can be seen that semi-solid roll-casting AZ91D strips have significant plasticity. The largest deformation of AZ91D strips is by cold rolling can reach as high as $18 \%$ and by hot rolling can reach $21 \%$ with one-pass roller. In addition, the total deformation of cold rolling and hot rolling can be up to $28 \%$ and $47 \%$ respectively with three-pass. The largest deformation of AZ31 strips can reach as high as $57 \%$ after two-pass. The samples are shown in Fig.24. It can be seen that the surface and edges of the samples are well and only little crack in the edges.

\begin{tabular}{|c|c|c|c|c|}
\hline \multicolumn{2}{|l|}{ No. } & 1 & 2 & 3 \\
\hline \multicolumn{2}{|l|}{ Material } & AZ91D & AZ91D & AZ31B \\
\hline \multicolumn{2}{|c|}{ Deformation condition } & Cold rolling & Hot rolling & Hot rolling \\
\hline \multicolumn{2}{|c|}{ Temperature/K } & $\mathrm{RT}$ & 613 & 623 \\
\hline \multicolumn{2}{|c|}{ Original Thickness $/ \mathrm{mm}$} & 3.2 & 3.3 & 2.3 \\
\hline \multirow{2}{*}{ First pass } & Thickness/mm & 2.6 & 2.6 & 1.6 \\
\hline & $\psi / \%$ & 18 & 21 & 30 \\
\hline \multirow{2}{*}{ Second pass } & Thickness $/ \mathrm{mm}$ & 2.3 & 2.12 & 1.0 \\
\hline & $\psi / \%$ & 11 & 18 & 37.5 \\
\hline \multirow{2}{*}{ Third pass } & Thickness $/ \mathrm{mm}$ & & 1.75 & \\
\hline & $\psi / \%$ & & 17 & \\
\hline \multicolumn{2}{|c|}{ Total deformation $\psi / \%$} & 28 & 47 & 57 \\
\hline
\end{tabular}

Table 6 . The experimental results of semi-solid roll-casing strips by hot and cold rolling 

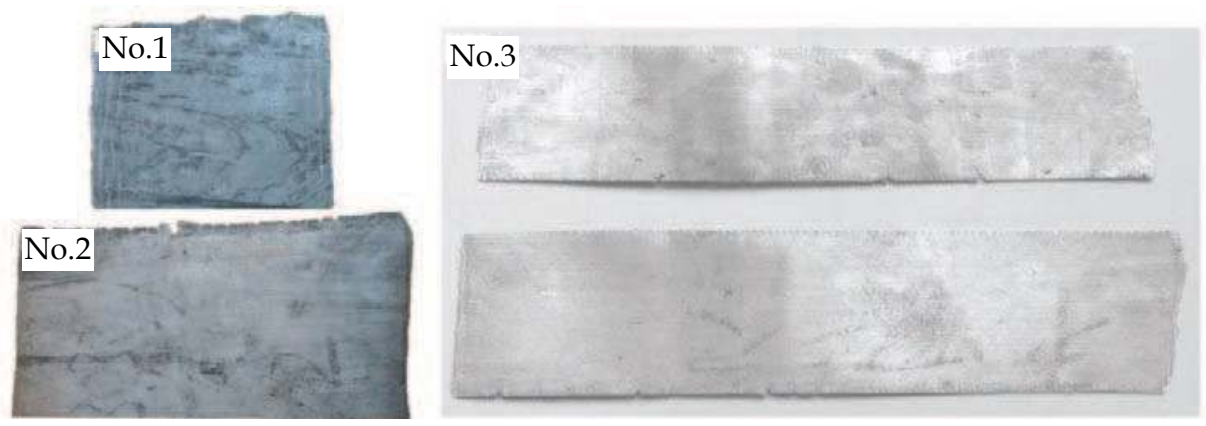

Fig. 24. Samples by hot and cold rolling: (No.1) AZ91D; (No.2) AZ91D; (No.3) AZ31B

The microstructure of cross and lengthwise section by hot rolling are shown in Fig.25. Compared Fig. 25 with Fig.22, there are many changes in the microstructure before and after hot rolling. The grains have been crushed. And there are difference of the microstructure on cross and lengthwise section; the grains in cross section are crushed due to the reduction of roller, and the grains in lengthwise section are lengthened along roll direction.
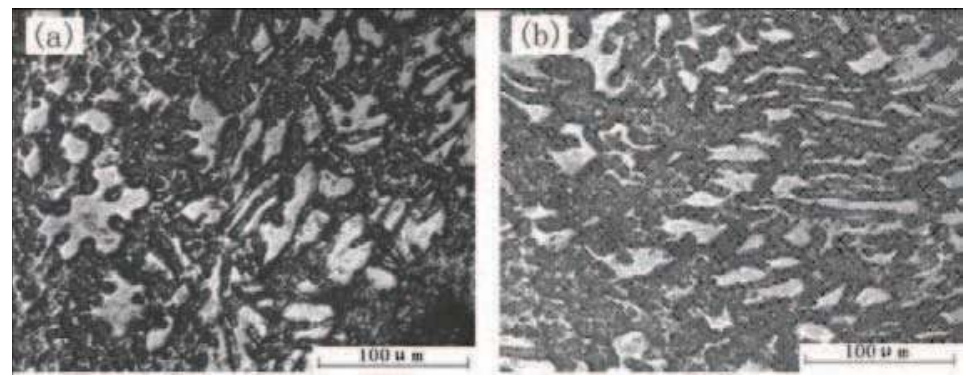

Fig. 25. Microstructure of samples after hot rolling: (a) cross section (b) lengthwise section

\subsection{Punching process test of strips}

The punching experiment was made for further examining the forming property of the semi-solid strips after hot rolling as shown in Fig.26. The testing results indicate that the AZ31B strips through further hot rolling still have better forming property.

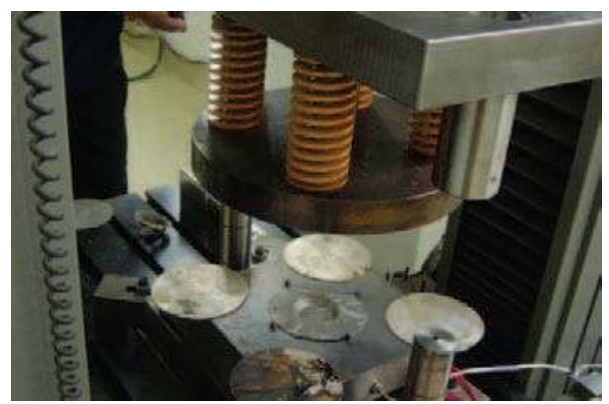

Fig. 26. The punching processing test device 


\section{Acknowledgement}

The authors greatly acknowledge the sponsor of the National Natural Science Foundation of China (NSFC), Sponsor No. 51075006, 50374014, 50674017.

\section{Conclusion}

Semi-solid magnesium alloys slurry preparation by DCT method and continuous rollcasting process were studied based on numerical simulation and experiment in this chapter. The main research results are as follow:

1. The position of wedge block, gap size, fall head and the height of wedge block have great influence on the molten alloy flow in damper cooling tube based on the numerical simulation.

2. The position of wedge block has great effect on the cooling tube, when the wedge block is located at the outlet of tube, the mixture of the semi-solid slurry is more homogeneous; gap size plays important role in the cooling and stirring ability of tube and the optimum gap size is 4-6mm for getting better stirring and cooling; the height of fall head must be higher than $500 \mathrm{~mm}$ and the wedge block height should be less than $100 \mathrm{~mm}$.

3. The AZ91D magnesium alloy billets with thin and homogeneous microstructure prepared by the DCT method were obtained when the fall head is $700 \mathrm{~mm}$, which indicates that the numerical simulation results is accorded with the experimental results and the DCT method is an effective way for preparing the semi-solid slurry.

4. Numerical simulation of semi-solid magnesium roll-casting process was studied using FLOW3D. It was found that the pouring temperature has great influence on the temperature and solid fraction in molten pool and the final point of solidification. With decreasing the pouring temperature, the length of rolling zone and roll-casting load increase. So, the proper velocity should be chosen according the specific condition, in order to guarantee the quality of strips.

5. The semi-solid AZ91D roll-casting strips were obtained by horizontal double rollers roll-casting device. The microstructure of before roll-casting is clear polygonal primary crystal, but the after roll-casting is globular and closely resembles globular crystal. And the strips had good processability and plasticity.

6. The largest deformation of AZ91D strips is by cold rolling can reach as high as $18 \%$ and by hot rolling can reach $21 \%$ with one-pass roller. In addition, the total deformation of cold rolling and hot rolling can be up to $28 \%$ and $47 \%$ respectively. The largest deformation of AZ31 strips by hot rolling can reach as high as $57 \%$

\section{References}

Spencer, D.B.; Mehrabian, R. \& Flemings, M.C. (1972). Rheological behavior of Sn-15Pb in the crystallization range. Metallurgical Transactions, Vol. 3, pp. 1925-1932.

Flemings, M.C. (1991). Behavior of metal alloys in the semisolid state. Metallurgical Transactions, Vol. 22B, pp. 269-293.

Xie, S.S. (2002) The Overview of Study and Application of Semi-solid Metals Processing Technology. Journal of Plasticity Engineering, Vol. 9, pp. 1-16. 
Hall, K.; Kaufmann, R.H., et al. (2000) Detailed processing and cost considerations for newrheocasting of light metal alloys. Proceedings of the $6^{\text {th }}$ International Conference of Semi-solid Processing of Alloy and Composites, pp.23-28, Turin Italy.

Haga, T.; Suzuki, S. (2001) Casting of Aluminum Alloy Ingots for Thixoforming Using A Cooling Slope. Journal of materials processing technology, Vol. 118, pp. 169-172.

Haga, T.; Tkahashi, K.; Ikawa, M. et al (2004) Twin roll casting of aluminum alloy strips. Journal of Materials Processing Technology, Vol. 153-154, pp. 42-47.

He, Y.F.; Xing, S.M., et al. (2009) Semi-solid Casting of High Speed Steel Ingots Using Inclined Slope Pre-crystallization Method. Journal of Wuhan University of TechnologyMater. Sci. Ed, Vol. 24, pp. 750-752.

Jorstad, J.; Thieman, M. \& Kamm, R. (2002). SLC- The newest and most economical approach to semi-solid metal casting. Proceedings of the $7^{\text {th }}$ International Conference on Semi-solid Processing of Alloys and Composites, pp. 701-706, Tsukuba Japan.

Xie, S.S.; Yang, H.Q., et al. (2004) Damper cooling tube method to manufacture semi-solid slurry of magnesium alloy. Proceedings of the $8^{\text {th }}$ International Conference of Semi-solid Processing of Alloy and Composites, Limassol, Cyprus.

Xie, S.S.; Yang, H.Q., et al. (2006) Numerical Simulation and Parameters Optimization of Preparation of AZ91D Magnesium Alloy Semi-solid Slurry by Damper Cooling Tube Method. The Chinese Journal of Nonferrous Metals, Vol. 16, pp. 488-493.

Xie, S.S.; Huang, G.J., et al. (2007) Study on Numerical Simulation and Experiment of Fabrication Magnesium Semisolid Slurry by Damper Cooling Tube Method. The $10^{\text {th }}$ International Conference on Numerical Methods in Industrial Forming Processes, Faculty of Engineering, University of Porto , Portugal.

Yang, H.Q.; Xie, S.S., et al. (2007) Numerical Simulation of the Preparation of Semi-solid Metal Slurry with Damper Cooling Tube Method. Journal of University of Science and Technology Beijing, Vol.14, pp. 443-448.

Launder, B.E.; Spalding, D.B. (1972). Lectures in Mathematical Models of Turbulence. Academic Press, London.

Xie, S.S.; Geng, M.P., et al. (2005) A New Technique of Casting-rolling Strips for Semi-solid Magnesium Alloys [J]. Material Science and Technology, Vol. 21, pp. 785-787.

Xie, S.S.; Yang, H.Q., et al. (2006) Numerical simulation of semi-solid Magnesium alloy in continuous roll-casting process. International Conference on Semi-Solid Processing of Alloys and Composites, Trans Tech Publications, Switzerland, Solid State Phenomena, Vol. 116-117, pp. 583-586.

Xie, S.S.; Yang, H.Q., et al. (2007) Numerical Simulation of Semi-solid Magnesium Alloy in Continuous Casting Process. Journal of Plasticity Engineering, Vol. 14, pp. 80-88.

Xie, S.S.; He, Y.F., et al. (2008) Study on Semi-solid Continuous Roll-casting Strips of AZ91D Magnesium Alloy. Proceedings of the 10 th International Conference of Semi-solid Processing of Alloy and Composites, Solid State Phenomena, Vol. 141-143, pp. 469-473.

Zhang, Y.; Geng, M.P., et al. (2008) Influence of Processing Parameters on Microstructure of Casting Rolling Semi-solid AZ91D Magnesium Alloy. Proceedings of the 10 $10^{\text {th }}$ International Conference of Semi-solid Processing of Alloy and Composites, Solid State Phenomena, Vol. 141-143, pp. 535-538.

Zhang, Y.; Xu, J.H., et al. (2007) Study on Rheocasting-rolling of Semi-solid AZ31B Magnesium Alloy. Trans. Nonferrous Met. Soc. China, Vol. 17, pp. s814-s817. 


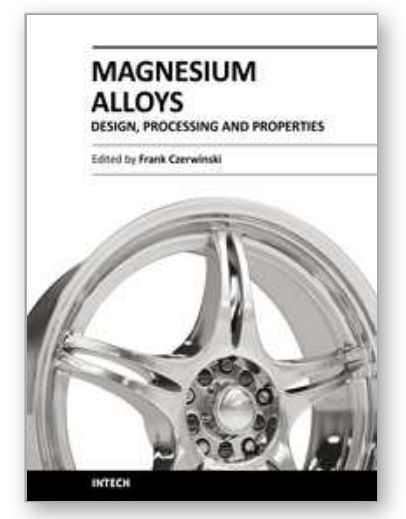

\author{
Magnesium Alloys - Design, Processing and Properties \\ Edited by Frank Czerwinski
}

ISBN 978-953-307-520-4

Hard cover, 526 pages

Publisher InTech

Published online 14, January, 2011

Published in print edition January, 2011

Scientists and engineers for decades searched to utilize magnesium, known of its low density, for lightweighting in many industrial sectors. This book provides a broad review of recent global developments in theory and practice of modern magnesium alloys. It covers fundamental aspects of alloy strengthening, recrystallization, details of microstructure and a unique role of grain refinement. The theory is linked with elements of alloy design and specific properties, including fatigue and creep resistance. Also technologies of alloy formation and processing, such as sheet rolling, semi-solid forming, welding and joining are considered. An opportunity of creation the metal matrix composite based on magnesium matrix is described along with carbon nanotubes as an effective reinforcement. A mixture of science and technology makes this book very useful for professionals from academia and industry.

\title{
How to reference
}

In order to correctly reference this scholarly work, feel free to copy and paste the following:

Shuisheng Xie, Youfeng He and Xujun Mi (2011). Study on Semi-Solid Magnesium Alloys Slurry Preparation and Continuous Roll-Casting Process, Magnesium Alloys - Design, Processing and Properties, Frank Czerwinski (Ed.), ISBN: 978-953-307-520-4, InTech, Available from:

http://www.intechopen.com/books/magnesium-alloys-design-processing-and-properties/study-on-semi-solidmagnesium-alloys-slurry-preparation-and-continuous-roll-casting-process

\section{INTECH}

open science | open minds

\section{InTech Europe}

University Campus STeP Ri

Slavka Krautzeka 83/A

51000 Rijeka, Croatia

Phone: +385 (51) 770447

Fax: +385 (51) 686166

www.intechopen.com

\section{InTech China}

Unit 405, Office Block, Hotel Equatorial Shanghai

No.65, Yan An Road (West), Shanghai, 200040, China 中国上海市延安西路65号上海国际贵都大饭店办公楼 405 单元

Phone: +86-21-62489820

Fax: $+86-21-62489821$ 
(C) 2011 The Author(s). Licensee IntechOpen. This chapter is distributed under the terms of the Creative Commons Attribution-NonCommercialShareAlike-3.0 License, which permits use, distribution and reproduction for non-commercial purposes, provided the original is properly cited and derivative works building on this content are distributed under the same license. 